\title{
Equation for estimating stem volume for Agar tree(Aquilaria malaccensis Lamk) grown in the plantationsin Bangladesh
}

\author{
S.M.Z. Islam ${ }^{1,2^{*}}$ and M.A.M. Chowdhury ${ }^{2}$ \\ 1, 2 Forest Inventory Division, Bangladesh Forest Research Institute, Chittagong, Bangladesh \\ ${ }^{2}$ Jamal Nazrul Islam Research Centre for Mathematical and Physical Sciences, University of \\ Chittagong, Chittagong-4331, Bangladesh
}

Date Received:04-10-2017 Date Accepted: 01-12-2017

\begin{abstract}
Agar tree (Aquilaria malaccensis Lamk, Family- Thymeleaceae) has drawn unique position due to the production of world's most expensive essential oil used in fragrances and also medicine. It is one of the most valuable and economically important commercial tree speciesplanted in some potential forest areas of Bangladesh. The main aim of this study is to develop mathematical models for total volume estimation of Agar tree. In order to meet the requirements we have selected 21 models of volume equation which are tested by regression technique. Among them for one way volume equation $V=a+b D+c D^{2}$ and for two way volume equation $V=a+b D+c H+d D^{2} H$ appeared to the best model for estimating the Agar tree volume.From these models conversion factors equation $F_{r}=D /\left(a+b D+c D^{2}\right)(r=11,13,15)$ has been determined to estimate under bark volume and under bark volume of different top end diameters of 11,13 , and 15 centimeters.
\end{abstract}

Keywords:Aquilaria malaccensis, model,stem volume andvalidation

\section{Introduction}

Volume equations play an important role in forest management. The importance ofvolume equations are indicated by the existence of numerous such equations andthe constant search for their improvement.Among various characteristics volume estimation is the most important features to know. For more than a century, researchers make an effort to estimate the volume of different trees over the time. Now a days reasonably a number of volume equations have been used to estimate tree and stand volume, and have played a significant role in forest inventories and management.Sustainable forest management requires among othersknowledge on the total volume of the growing forest stock.Usually volume is estimated as total volume per unit area,whereby models predicting total tree volume of individualtrees are used. Studies of tree volume began in the early nineteenth century. A numerous equations has been published in forest literature (Spurr 1952, Clutter et al. 1983, Avery \& Burkhart 2002, Abel 2014,Latif \& Islam 2014). Because of inherent morphological differences among tree species, it is generally necessary to develop separate standard volume equations for each species or closely related species group (Burkhart \& Gregoire 1994). These are simple methods and tools that can be used to obtain individual tree volume and the volumes of entire stands. Such information is vital for forest management. The objective of any volume equations to provide accurate estimates with acceptable levels of local bias over the entirediameter range in the data.Equations that provide accurate predictions of volumewithout local bias over the entire range of diameter are one of the basic building blocks of a forest growth and yield simulation system (Bi \& Hamilton 1998).

*Correspondence: zahir.fid.bfri@gmail.com

Tel: 08801837000010

ISSN 2235-9370 Print / ISSN 2235-9362 Online CUniversity of Sri Jayewardenepura 
Development of sound management practice is oneof the major priorities oftheforestry sector. Tree volume equation provide to the tree biomass and carbon estimation in non-destructive way.Even though volume equations have been studied for many years, but still the research is continuing even more vitally. One reason is that there is no single theory in volume equations that can be used satisfactorily for all tree species (Clutter et al. 1983; Muhairwe 1999). Another reason is that volume equations are required to be increasingly accurate and flexible in their predictions. Forest measurement needs to be improved because market requirements for timber have become more specific in recent years.

Volume equations have been developed more than forty different important tree species in Bangladesh (Latif and Islam 2014; Islamet al. 2014). A considerable amount of work on volume has been done by researchers of Bangladesh Forest Research Institute (BFRI). However, there have been no studies on volume equation for Agar tree(Aquilaria malaccensis Lamk) plantations in Bangladesh.

Agar treeis an evergreen tropical tree species found in the Aquilaria species of the Thymelaeaceae family. The most highly valuable non-timber forest products itisharvested from tropical forests and used in the manufacture of perfume, incense, traditional medicine, and other commercial products by Muslims and Asian Buddhists (Turjaman et al.,2006). The aromatic resin known as locally 'agar' yield an essential oil that is a key perfume ingredient through distillation, meanwhile, incense are commonly processed from distillation residues and lesser quality material. Agar tree(A. malaccensis Lamk) is a major producer of agar wood in Bangladesh for international trade. Natural populations of Agar treeare distributed in south and Southeast Asia and in Bangladesh it occurs mostly in the forests of Sylhet, Chittagong and Chittagong Hill Tracts (Rahman and Basak 1980). This tree is also found in Nepal, Bhutan, North Eastern India (Assam, Arunachal Pradesh, Nagaland, Meghalaya, Mizoram, Manipur, and Tripura), Myanmar, Thailand, Laos, Indonesia, Malaysia, Vietnam, Cambodia, South-Eastern China, Brunai Darus-Salam, The Philippines, Islands of East Indias and Papua New Guinea (Baksha et al. 2009, Burkhill 1966). Agar tree (A. malaccensis Lamk)is known to be one of the most important species of commerce and valued for production of its impregnated resinous heart wood that gives fragrance.

Bangladesh has favorable climate for Agar tree plantation(Baksha et al. 2009). The Bangladesh Forest Department has taken an initiative to expand and popularize Agar plantation in the country from 1998-2005 considering the economic value of such a unique forest resource, particularly for its demand in the international market (BFD).About 800 ha of land have been planted under this project. Among these plantations 324 ha are in Sylhet, 282 in Chittagong, 189 in Cox's Bazar and 5 ha in and Chittagong Hill Tracts (Baksha et al. 2009).Following this it has been extensively used as a plantation species different NGOs (BRAC) and private planters. The aim of the present study is to develop volume equations forAgar tree(Aquilaria malaccensis Lamk) plantations in the potential forest areas of Bangladesh.

\section{Material and Methods}

\subsection{Study area}

The Bangladesh Forest Department has taken an initiative to expand and popularize agar plantation in the country considering the economic value of such a unique forest resource, particularly for its demand in the international market. They cultivate Agar tree under Agar plantation project in many potential places in Sylhet, Chittagong, Cox's Bazar and in the districts of Chittagong Hill 
Tracts. The study has been conducted in the remnant the existence Agar tree plantationin several forest beat of these forest areas.

\subsection{Measurement of trees}

Data were collected from available plantation in Sylhet, Chittagong, Cox's Bazar and the districts of Chittagong Hill Tracts. 250 standing Agar trees in representing different diameter classes were selected at random for preparation of mathematical volume equation and tables. Trees diameter at breast height (Dbh) in $\mathrm{cm}$ and total height in meter were measured with diameter tape and Hagaaltimeter respectively. The collected data were categorized on the basis of Dbhand height of the trees. The Dbh-height class distribution of the sample trees are given in Table 1. The diameter and bark thickness at one meter intervals up to $7.5 \mathrm{~cm}$ top end diameterin the stem were measured by climbing the trees with a ladder. The mid diameter of big branches also measure for branch volume. The bark thicknesses of the samples were measured with a bark gauge.Summary statistics of the collected representative trees are shown in Table 2.

Table 1:Dbhand total height class distribution of the sampled trees selected for volume estimation of Agar tree(Aquilaria malaccensis Lamk) plantation in Bangladesh.

\begin{tabular}{|c|c|c|c|c|c|c|c|}
\hline \multirow[t]{2}{*}{$\overline{\text { Dbhclasses }(\mathrm{cm})}$} & \multicolumn{6}{|c|}{ Total height class } & \multirow{2}{*}{$\begin{array}{c}\text { Total } \\
\text { Number of } \\
\text { trees }\end{array}$} \\
\hline & $<5$ & $(5-8)$ & $(8-11)$ & $(11-14)$ & {$[14-17)$} & $\geq 17$ & \\
\hline$[8-11)$ & 4 & 9 & & & & & 13 \\
\hline$[11-14)$ & & 12 & 18 & 2 & & & 32 \\
\hline [14-17) & & 5 & 30 & 15 & & & 50 \\
\hline$[17-20)$ & & 1 & 20 & 36 & 3 & & 60 \\
\hline$[20-23)$ & & & 4 & 30 & 15 & 1 & 50 \\
\hline$[23-26)$ & & & & 6 & 19 & 7 & 32 \\
\hline$\geq 26$ & & & & & 9 & 4 & 13 \\
\hline & 4 & 27 & 72 & 89 & 46 & 12 & 250 \\
\hline
\end{tabular}

Table 2:Summary statistics of Dbh and height of sample trees.

\begin{tabular}{lllllll}
\hline Variables & $\mathrm{n}$ & Mean & Min & Max & S.E & SD \\
\hline Dbh $(\mathrm{cm})$ & 250 & 18.4 & 8.6 & 38.5 & 0.3 & 5.4 \\
Height $(\mathrm{m})$ & 250 & 11.5 & 4.0 & 19.5 & 0.2 & 3.3 \\
\hline
\end{tabular}

\subsection{Compilation of data}

Volumes of all sections except top and bottom section were determined by using the crosssectional areas of the two ends of each section following Smalian's formula,

$$
\text { Cubic volume }=[(B+b) / 2] L
$$

Where:

$B=$ the cross-sectional area at the large end of the log

$b=$ the cross-sectional area at the small end of the log

$L=\log$ length 
In determining the volume of bottom sections (Frustum), the volume of a conoidoid of basal diameter $D$, top diameter $d$ and height $H$ is calculated as: $V=\frac{\pi H}{12} \times\left(D^{2}+D \times d+d^{2}\right)$. Assuming the top section as cone the volume was computed to one third of the cylindrical volume of the portion. We considered the top end diameter measurement for each tree as the base diameter of the cone. The branch log volume calculated by cylindrical volume formula. In computing the under bark volume of the tree the volume of top section i.e. cone was ignored. The volume of the tree is the sum of the volume of total sections and big branches found in a tree. The individual tree volumes $(V), D b h$ $(D)$ and total height $(H)$ were variable in regression techniques using various functions and transformations as required in the models.

\subsection{Computation of volume function}

Multiple regression analysis techniques were used to select the best suited model equations. The following 21 models (Clutter et al. 1983; Bi and Hamilton 1998)were tested to select the equation of best fit with different variables as follows.

$$
\begin{aligned}
& V=a+b D \\
& V=a+b D+c D^{2} \\
& V=a+b D^{2} \\
& V=a D+b D^{2} \\
& V=a D+b D^{-1} \\
& V=a D+b D^{-2} \\
& \log (V)=a+b D \\
& V=a+b \log (D) \\
& \log (V)=a+b \log (D) \\
& V=a+b D^{2} H \\
& V=a+b D+c H \\
& V=a+b D+c D^{2} H \\
& V=a+b D+c D H \\
& V=a+b D+c H+d D H \\
& V=a+b D+c H+d D^{2} H \\
& V=a+b D^{2}+c H+d D H \\
& V=a+b D^{2}+c H+d D^{2} H \\
& V=a+b D^{2}+c D H+d D^{2} H \\
& V=a+b \log (D)+c \log (H) \\
& \log (V)=a+b \log (D)+c \log (H) \\
& V=a+b D^{-1}+c H^{-1} \\
& V=a
\end{aligned}
$$


Where:

$V=$ Total volume over bark in cubic meters

$D=$ Diameter at breast height in centimeters

$H=$ Total height in meters

$a=$ Regression constant

$b, c, d=$ Regression coefficients

The logarithmic functions are to the base e

Following original and transformed variables were used to select the best suited regression models. Dependent variables: $V, \log (V)$

Independent variables: $D, D, D^{-1}, D^{-2}, H, H^{-1}, D H, D^{2} H, \log (D), \log (H)$

The dependent variables mentioned above were regressed with the independent variables.

The equations of the best fit based on the highest multiple coefficients of determination $\left(R^{2}\right)$; F-ratio, lowest residual mean square (RMSE), AIC value and Durbin-Watson statistic were chosen. Models for estimation of the total volume over bark were selected and to estimate under bark volume and under bark volume to top end diameters of approximately 11, 13and $15 \mathrm{~cm}$ were also estimated.

\subsection{Model Validation}

Statistical validation

The best suited models were tested with a set of data recollected from 30 trees of different diameter class and complied in the same procedure as earlier. The actual volumes of these trees were collectively compared with the corresponding volume predicted by the selected models. The independent tests for validation were the absolute paired t-test, chi-square test,deviation percentand 45 degree line test (Islam et al. 1992).

\subsection{Data Analysis}

Data collected were organized and screened (removing the outliers) for analysis. Descriptive statistical analysis was further carried out in order to summarize the data. All analysis carried out were conducted using MS Excel 2013, SPSS 17 Inc and EViews (Quantitative Micro Software, LLC) statistical package version 9.

\section{Results and Discussions}

\subsection{Dependent and independent variables}

For efficient and accurate tree volume modeling, field data must be statistically and biologically valid before using them to develop models. In this study the data used were carefully obtained from the field and subjected to biological validation and the results indicated a normal distribution pattern as lower diameter to highest diameter. The collected data shows that number of the trees are increased lower diameter to mid-diameter simultaneously decreases from mid-diameter to highest diameter (Figure 1). Hence the number samples normally distributed with independent variable. 


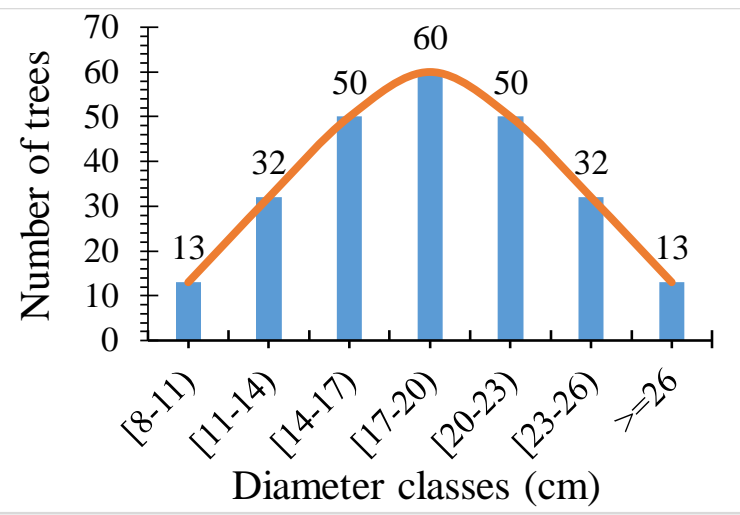

(a)

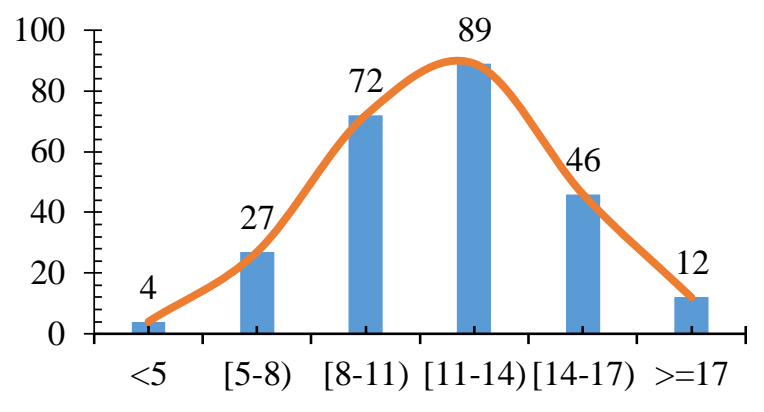

Height classes (m)

(b)

Figure 1:Distribution of sample trees by (a) diameter and (b) height classes for estimating total volume of Agar tree (Aquilaria malaccensis Lamk).

Total volume over bark has been calculated from total of 250 individual trees in this study. The scatter plot of the individual actual total volume and Dbh\& height for individual trees of Agar treeplantations in Bangladesh is presented by Figure 2. It is also scatter relationship between dependent variable (volume) and independent variables (Dbh and height) using the actual field data before model fitting. From the figure it is shows that tree volume increased rapidly as Dbh increased; however, as the Dbh increased further, the increase in tree volume slowed down and the volumeDbhcurve became less steep (Figure 2a). It is also shows that tree volume increased slowly as height increased upto $15 \mathrm{~m}$, then it was increased rapidly(Figure $2 \mathrm{~b}$ ). Present study performed to develop one way and two way volume equation of Agar tree by using these variables.

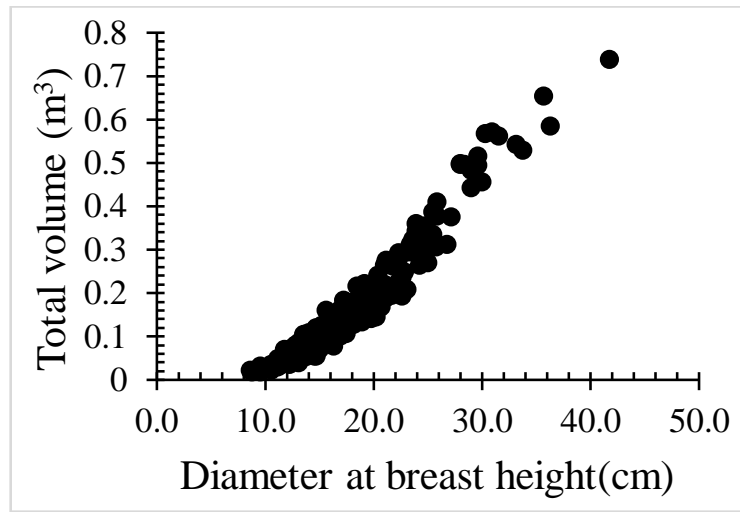

(a)

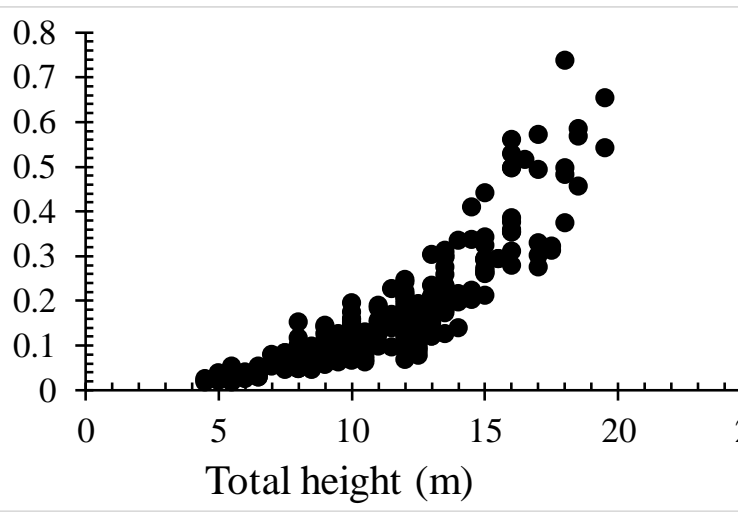

(b)

Figure 2:The scatter plot of the individual actual total volume with independent variable (a) diameter and (b) height of Agar tree(Aquilaria malaccensis Lamk). 


\subsection{Estimated parameters}

Estimated parameters of fitted models are presented in Table 3. The 21 models were tested to develop equation for total volume of Agar tree. The first 9 models are one way volume models and the 12 remaining models at the bottom are two way volume models. Nine models had two, seven models had three and five models had four estimated parameters. The standard errors given in the table show that all the partial regression coefficients were significant except for model 6.

Table 3:Values of coefficients for different models obtained for fitting data set.

\begin{tabular}{ccccccccc}
\hline Model & \multicolumn{3}{c}{ Estimated parameter } & \multicolumn{3}{c}{ Standard error of parameter } \\
\cline { 2 - 8 } No & $\mathrm{a}$ & $\mathrm{b}$ & $\mathrm{c}$ & $\mathrm{d}$ & $\mathrm{a}$ & $\mathrm{b}$ & $\mathrm{c}$ & $\mathrm{d}$ \\
\hline 1 & -0.2386 & 0.0226 & & & 0.0076 & 0.0004 & & \\
2 & -0.1226 & 0.0105 & 0.0003 & & 0.0182 & $1.80 \mathrm{E}-03$ & $4.24 \mathrm{E}-05$ & \\
3 & -0.0188 & 0.0005 & & & 0.0039 & $9.10 \mathrm{E}-06$ & & \\
4 & -0.0014 & 0.0006 & & & 0.0004 & $1.75 \mathrm{E}-05$ & & \\
5 & 0.0159 & -1.9163 & & & 0.0003 & 0.0812 & & \\
6 & 0.0135 & -17.5016 & & & 0.0002 & 1.0054 & & \\
7 & -4.3638 & 0.1291 & & & 0.0601 & 0.0032 & & \\
8 & -0.9864 & 0.4058 & & & 0.0319 & 0.0111 & & \\
9 & -9.2309 & 2.5244 & & & 0.1146 & 0.0398 & & \\
10 & 0.0340 & $2.97 \mathrm{E}-05$ & & & 0.0030 & $4.77 \mathrm{E}-07$ & & \\
11 & -0.2464 & 0.0211 & 0.0032 & & 0.0079 & 0.0007 & 0.0011 & \\
12 & -0.0900 & 0.0100 & $1.72 \mathrm{E}-05$ & & 0.0139 & 0.0011 & $1.44 \mathrm{E}-06$ & \\
13 & -0.1553 & 0.0122 & 0.0005 & & 0.0118 & 0.0013 & $5.63 \mathrm{E}-05$ & \\
14 & -0.0139 & 0.0051 & -0.0134 & 0.0011 & 0.0202 & 0.0014 & 0.0016 & $9.16 \mathrm{E}-05$ \\
15 & -0.0975 & 0.0094 & 0.0018 & $1.68 \mathrm{E}-05$ & 0.0143 & 0.0011 & 0.0009 & $1.45 \mathrm{E}-06$ \\
16 & 0.0016 & 0.0002 & -0.0074 & 0.0009 & 0.0148 & $4.41 \mathrm{E}-05$ & 0.0026 & 0.0001 \\
17 & -0.0542 & 0.0003 & 0.0065 & $8.10 \mathrm{E}-06$ & 0.0114 & $4.57 \mathrm{E}-05$ & 0.0010 & $2.83 \mathrm{E}-06$ \\
18 & -0.0386 & 0.0003 & 0.0005 & $1.82 \mathrm{E}-07$ & 0.0080 & $4.19 \mathrm{E}-05$ & $5.83 \mathrm{E}-05$ & $3.17 \mathrm{E}-06$ \\
19 & -0.9885 & 0.4141 & -0.0091 & & 0.0322 & 0.0202 & 0.0184 & \\
20 & -9.0504 & 1.8123 & 0.7766 & & 0.0773 & 0.0486 & 0.0443 & \\
21 & 0.5458 & -6.7319 & 0.3140 & & 0.0157 & 0.4592 & 0.2269 & \\
\hline
\end{tabular}

Table 4 compares the fit statistics for each of the equations except model 6 used. The $\mathrm{R}^{2}$ values were generally high and acceptable for all the equations except model 7, 8, 19 and 21 (Considered only $\mathrm{R}^{2} \geq 0.9$ ) while $R M S E$ values were very low except for model 9 and 20 . In this table also shows that $A I C$ values are low which are ranked as closed to zero. The positive serial correlation attains in all models as Durbin-Watson statistic measuresbelongs to $(0,2)$. Final ranking showed that model 2 ranked first for one way volume prediction followed by model 9, 1, 3, 4 and 5. Similarly, model 15 ranked first for two way volume prediction followed by model 20, 13, 10, 12, 17, 11, 14, 16 and 18 . 
Table 4:Fit statistics for volume equations of Agar tree(Aquilaria malaccensis Lamk).

\begin{tabular}{cccccccc}
\hline Models No & df & $R^{2}$ & $R M S E$ & $A I C$ & $D W$ & $\sum$ Rank & Final rank \\
\hline One way & & & & & & & \\
1 & 248 & $0.93(3)$ & $0.03(1)$ & $-3.9(4)$ & 1.6 & 8 & 3 \\
2 & 247 & $0.95(1)$ & $0.03(1)$ & $-3.1(2)$ & 1.6 & 4 & 1 \\
3 & 248 & $0.93(3)$ & $0.03(1)$ & $-3.9(4)$ & 1.5 & 8 & 3 \\
4 & 248 & $0.93(3)$ & $0.03(1)$ & $-3.9(4)$ & 1.5 & 8 & 3 \\
5 & 248 & $0.90(4)$ & $0.04(2)$ & $-3.5(3)$ & 1.4 & 9 & 4 \\
7 & 248 & 0.87 & 0.27 & 0.2 & 1.1 & & \\
8 & 248 & 0.84 & 0.05 & -3.1 & 1.4 & & \\
9 & 248 & $0.94(2)$ & $0.18(3)$ & $-0.5(1)$ & 1.3 & 6 & 2 \\
Two way & & & & & & & \\
10 & 248 & $0.94(4)$ & $0.03(1)$ & $-4.1(3)$ & 1.3 & 8 & 3 \\
11 & 247 & $0.93(5)$ & $0.03(1)$ & $-4.1(3)$ & 1.5 & 9 & 4 \\
12 & 247 & $0.96(2)$ & $0.03(1)$ & $-4.3(6)$ & 1.5 & 9 & 4 \\
13 & 247 & $0.95(3)$ & $0.03(1)$ & $-4.2(4)$ & 1.4 & 8 & 3 \\
14 & 246 & $0.96(2)$ & $0.03(1)$ & $-4.4(7)$ & 1.4 & 10 & 5 \\
15 & 246 & $0.97(1)$ & $0.03(1)$ & $-3.4(2)$ & 1.5 & 4 & 1 \\
16 & 246 & $0.96(2)$ & $0.03(1)$ & $-4.4(7)$ & 1.4 & 10 & 5 \\
17 & 246 & $0.95(3)$ & $0.03(1)$ & $-4.3(5)$ & 1.5 & 9 & 4 \\
18 & 246 & $0.96(2)$ & $0.03(1)$ & $-4.4(7)$ & 1.5 & 10 & 5 \\
19 & 247 & 0.84 & 0.05 & -3.1 & 1.4 & & \\
20 & 247 & $0.94(4)$ & $0.12(2)$ & $-1.3(1)$ & 1.6 & 7 & 2 \\
21 & 247 & 0.71 & 0.07 & -2.5 & 1.3 & & \\
\hline
\end{tabular}

Values in the parentheses give the ranks.

Model 2 and 15 performed the best fit model of one way and two way volume equations respectively. Figure 3 ( $a$ and $b$ ) illustrates the predicted volumes ofall trees in data set by the best fitted equation against the observed (actual) volumes. The figure shows that the volumes had a curvilinear relationship with diameter at breast height(D).

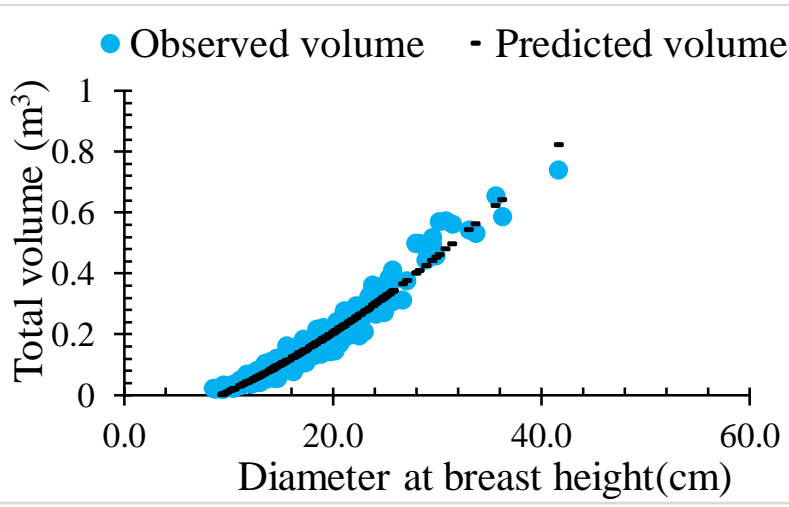

(a)

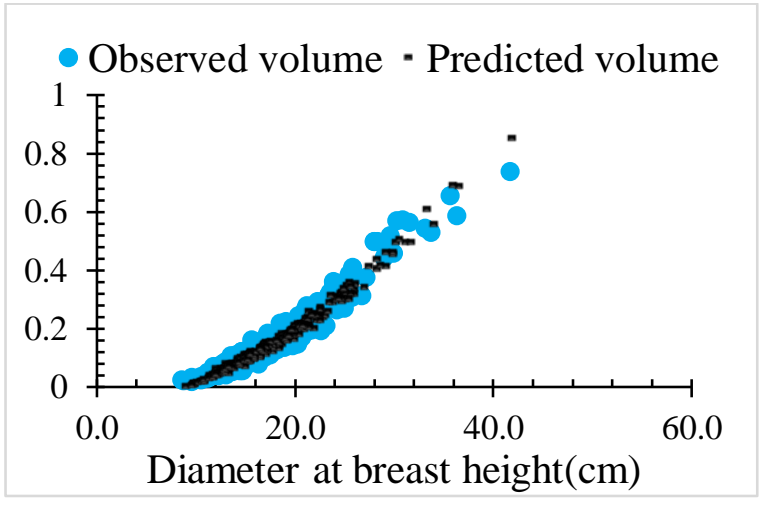

(b)

Figure 3:The scatter plot of the observed volume and predicted volume against D by selected model (a) one way and (b) two way of Agar tree(Aquilaria malaccensis Lamk). 


\subsection{Volume equations}

The regression models number 2 and 15 are best suited for one way and two way volume equations. The volume equations have been selected for estimation of the stem volume over bark (V) and conversion factors to estimate under bark stem volume and under bark volume to different top end diameters of 11,13 , and 15 centimeters form these models. The coefficients of determination for selected volume equations are 0.95 and 0.97 for one way and two way volume equations respectively. This means that the selected models describe over 95 (One way) and 97 (Two way) percent of the total variations. The best fitted models were selected for estimation of volume on Dbhand total height. The selected volume equations and conversion factor equations are given in Table 5.

Table 5:Selected tree volume equation for different proportion of Agar tree(Aquilaria malaccensis Lamk) planted in Bangladesh.

\begin{tabular}{lcc}
\hline Volume equations & R-squared & Observation \\
\hline $\begin{array}{l}V_{o b}=-0.122589+0.010486 \times \mathrm{D}+0.000292 \times D^{2} \\
\quad \times D^{2} \times \mathrm{H}\end{array}$ & 0.95 & 250 \\
$\begin{array}{r}V_{o b} \\
=-0.097547+0.009443 \times \mathrm{D}+0.001784 \times \mathrm{H}+0.000017\end{array}$ & 0.97 & 250 \\
$F_{u b}=0.801610+0.009261 \times \mathrm{D}-0.000120 \times D^{2}$ & 0.96 & 250 \\
$F_{11}=D /\left(16.213335-0.004324 \times \mathrm{D}+0.017740 \times D^{2}\right)$ & 0.90 & 250 \\
$F_{13}=D /\left(28.151346-0.553977 \times \mathrm{D}+0.023831 \times D^{2}\right)$ & 0.88 & 246 \\
$F_{15}=D /\left(62.345233-2.852730 \times \mathrm{D}+0.062848 \times D^{2}\right)$ & 0.91 & 241 \\
\hline
\end{tabular}

Where:

$\mathrm{D}=$ diameter at breast height in centimeter

$\mathrm{H}=$ total height in meters

$\mathrm{V}_{\mathrm{ob}}=$ total volume over-bark in cubic meters

$\mathrm{F}_{\mathrm{ub}}=$ conversion factor for under-bark volume

$F_{11}, F_{13}$ and $F_{15}=$ Conversion factors for the volume to $11 \mathrm{~cm}, 13 \mathrm{~cm}$ and $15 \mathrm{~cm}$ top end diameter respectively.

\subsection{Model Validation}

Statistical validation

The statistical requirement to best fitted models by considering those equations having the highest $R^{2}$ with lowest RMSE, Akaike Information Criterion (AIC) and the Durbin-Watson statistic $(D W)$ were tested. Results were presented in Table (4).

\section{Independent test}

The best suited volume equations for one way and two ways were tested with a set of data recollected from 30 trees of different diameter class and complied in the same procedure as earlier. The actual volumes of these trees were collectively compared with the corresponding volume predicted by the selected models. The independent tests for validation were the chi-square test, paired t-test, absolute deviation percent (\% AD) and 45 degree line test (Islam et al. 1992).

The computed chi-square, t-values, absolute deviation percent and slope for total height of Aquilaria malaccensis Lamk (Agar tree) are given Table (6). 
Table 6:Result of independent test.

\begin{tabular}{lcccc}
\hline Models & Chi & t & \%AD & Slope $^{\circ}$ \\
\hline One way & 0.127 & 0.34 & 0.17 & 44.4 \\
Two way & 0.128 & 0.49 & 0.12 & 43.7 \\
\hline
\end{tabular}

\section{Chi-square test}

The computed chi-square values of total volume over bark represent in Table 4 were less than the tabular values $X_{0.95,29}^{2}=17.71$. This implies that there is no significant difference between the actual values from the 30 test sample trees and the corresponding expected values as predicted by the selected models.

\section{Paired t-test}

The result of pared t-test for total volume over bark of $A$. malaccensis Lamk (Agar tree) planted in Bangladesh are given in Table 4computed t-ratio for all the estimation were less than the tabular values $t_{0.95,29}=2.045$. These imply that there were also no significant differences between the observed and predicted values. Thus the prediction models might be accepted.

Percent absolute deviation (\%AD) test

Absolute deviation percent $(\% \mathrm{AD})$ between the observed and predicted values for total volume over bark with diameter at breast height and dbh \& height for this study species was minimum, which also confirmed validity of the selected models.

\section{5- Degree line test}

Graphs comparing the observed values and the predicted values were plotted in the graph paper. The observed values and the predicted values yielded slops very closed to 45 degrees, which have been presented in Table 5. It was observed that the models tend to make an angle 45 degrees with the axes, meaning there were no significant difference between the actual and the predicted values.

Figure 4 shows that the predicted total volume over bark plotted against actual total volume over bark with 45-degree line test for best sited equation for tree volume estimation of Aquilaria malaccensis Lamk (Agar tree) planted in Bangladesh. 


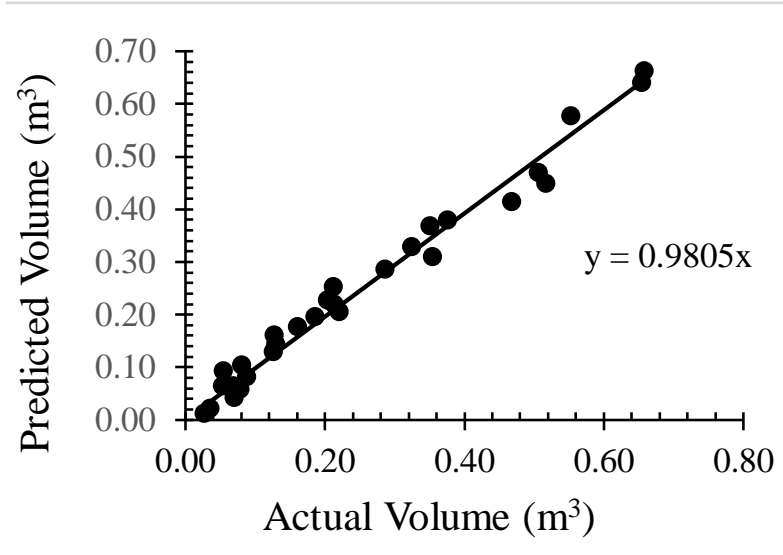

(a)

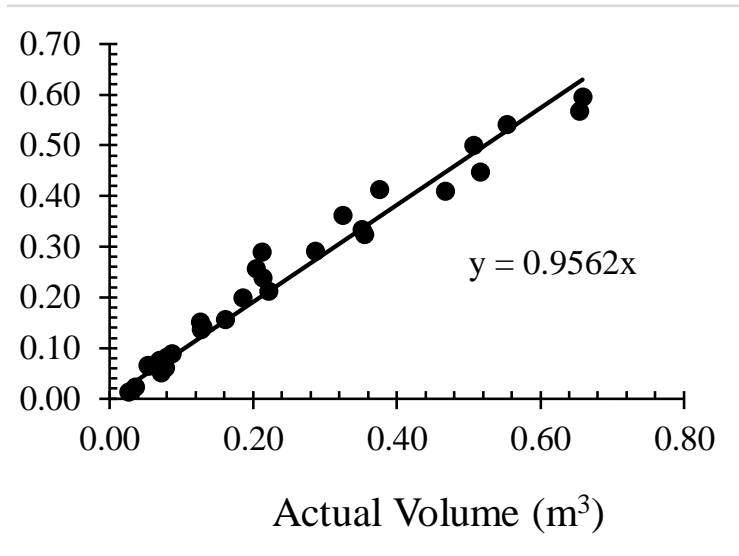

(b)

Figure 4: Observed vs. predicted tree volume over bark for the validation data set with 45-degree line test by selected models for (a) one way (b) two way volume of Aquilaria malaccensis Lamk (Agar tree) planted in Bangladesh.

\section{Confidence limits}

These volume equations should not be used to estimate volumes of individual trees in a stand. These tables may be used for the mean tree of a stand which may be multiplied by the number of stems to get the total volume of the stand. Estimation of the volumes for the trees outside the height and Dbh ranges shown in the stand table should only be done with caution.

Most of the models except models 19 and 21 were equally good fitted models with statistical and biological validation. The model 2 and model 15 are performed well in both the fitting and validation process for one way volume and two way volume respectively. Model 15 was the most precise and least biased model of them. It was ranked first by three statistics including $R^{2}, R M S E$ and $A I C$ (Table 4) which better than selected single-entry model. It is clear that the model of the form using $D b h, h t$ (height) and $D b h^{2} \times h t$ as the predictor variables provided good estimates of volume for agar tree planted in Bangladesh. In model 20 the natural logarithmic form using Dbh and height as the predictor variables provided also good estimates of volume. It was ranked second by three same statistics(Table 4).

\section{Conclusions}

It can be concluded from the study that the combined variable two equations (model 2 and 15) performed well in both the fitting and validation process. Therefore, it can be used to predict volume for Agar tree(A. malaccensis Lamk) in the study area. The contrasting results obtained between model fitting and validation emphasis the need for model validation as an important step in the model construction process in order to get the best choices.

\section{Acknowledgements}

The authors are thankful to the Ministry of Environment and Forestry of Bangladesh, for providing the study leave for this study. We are gratefully acknowledged to the Bangladesh Agriculture Research Council provided support for $\mathrm{PhD}$ project from which this research has come. We also grateful to all respective forest officers and stuffs of Bangladesh Forest Department who providing support during data collection of this study. 


\section{References}

Abel, M. M., Eliakimu, Z., Rogers, E. M., Ole, M. B., Tron, H. E., 2014. Volume Models for Single Trees in Tropical Rainforests in Tanzania. Journal of Energy and Natural Resources. Vol. 3, No. 5, 2014, pp. 66-76. doi: 10.11648/j.jenr.20140305.12

Avery, T.E., Burkhart, H.E. 2002. Forest measurements. Boston: McGraw-Hill. 456 pp.

Baksha, M. W., Akhter, S., Basak, A. C., Rahman, M. S., 2009. Bangladeshy agar chas o agar kutirsilpo (Agar cultivation and cottage industry in Bangladesh). Bangladesh Forest Research Institute, Chittagong 20pp (a booklet in Bangla)

HuiQuan, Bi,Hamilton, F., 1998. Stem volume equations for native tree species in southern New South Wales and Victoria. Australian Forestry 61(4): 275-286.

Burkhart, H. E., Gregoire, T. G. 1994. Handbook of statistics, vol. 12, chap. Forest biometrics, pp377-407. New York: Elsevier Science Publisher. (Vol. 12). New York: Elsevier Science Publisher.

Burkill, I. 1966. A Dictionary of Economic Products of the Malay Peninsula. Vol. I. Government of Malaysia and Singapore. The Ministry of Agricultural and Cooperatives, Kuala Lumpur. 198$206 \mathrm{pp}$.

Clutter, J.L.,Fortson, J.C.,Pienaar, L.V.,Brister, G.H.,Bailey, R.L., 1983. Timber management: A quantitative approach. John Wiley \& Sons, USA. 333 pp.

Islam, S. M. Z., Khan, M.I., Ahmed, K.U., 2014. Mathematical Volume equation and Table of Rubber tree, (Hevea brasiliensis. Muell Arg.), Bulletin No. 10. Forest Inventory Division. Bangladesh Forest Research Institute, P. O. Box-273, Chittagong - 4000, Bangladesh. 24 pp

Islam, S.S, Waziullah, A.K.M., Reza, N.A., 1992. Validation of the existing volume tables of Telyagarjan (Dipterocarpus turbinatus) in Bangladesh. Bangladesh J. For. Sci. 21(182):60-66

Latif, M.A., Islam, S. M. Z., 2014. Growth, Yield, Volume and Biomass Equation and Tables for Important Trees in Bangladesh. Forest Inventory Division. Bangladesh Forest Research Institute, P. O. Box-273, Chittagong - 4000, Bangladesh. 106 pp

Muhairwe, C.K., 1999. Taper equations for Eucalyptus pilularis and Eucalyptus grandis for the north coast in New South Wales, Australia. Forest Ecology and Management 113: 251-269.

Rahman, M.A., Basak, A.C., 1980. Agar production in agar trees by artificial inoculation and wounding. Bano Bigan Patrika 9 (1\&2): 86 - 93.

Spurr, S.H., 1952. Forest Inventory. Ronald Press, New York. 476pp.

Turjaman, M.,Santoso, E.,Sumarna, Y., 2006. Arbuscural mycorrhizal fungi increased early growth of Gaharu wood of Aquilaria malaccensis and A. crasna under greenhouse conditions. J. For. Res., 2: 139-148. 